\title{
Training Design Conception and Reflexive Practice: How to Answer Teachers' Questions?
}

\author{
Régine Clottu ${ }^{1,2}$ \\ ${ }^{1}$ Teaching and Research Units, University of Geneva, Switzerland \\ ${ }^{2}$ University of Teacher Education, State of Vaud, Switzerland
}

Copyright $\bigcirc 2017$ by authors, all rights reserved. Authors agree that this article remains permanently open access under the terms of the Creative Commons Attribution License 4.0 International License

\begin{abstract}
This research studies the practices related to the conception of training on demand in the field of continuous training of teachers. Training on demand adapts itself to the problems of professionals. The analysis of the demand faces the complexity of the different contexts as well as the diversity of professionals' questions. This paper emphasizes relevant elements based on a case study to show how the trainer who designs the concept takes into account factors present during the conception i.e. the various aspects of context, contents and learners. The method chosen for the research is qualitative and built related to a specific scholar context in which the teachers have difficulties in their daily work specifically in the field of French language. The training design provides various modalities including conferences, discussion groups, and support in the classes in the presence of the pupils. Different measures to support the teachers in regular classes are provided by specialized professionals. As the schoolchildren come from a great number of cultures, speak diverse languages and attend the courses of regular schools near their homes, this original design takes place in an inclusive context and aims at enabling the teachers to develop reflective practice.
\end{abstract}

Keywords Adult Education, Demand Analysis, Conception, Design, Inclusive School Context

\section{Introduction}

This research examines the specific practices related to the design of training in the field of teachers' continuous training in an inclusive school setting.

We focus our attention on a situation presented by school actors when they send a written request to the University of teacher education in Lausanne-Switzerland. In their specific scholar context, teachers have difficulties in their daily work particularly in the field of French language. A lot of pupils speak another language at home and have trouble learning to read. Different measures were carried into effect, but more support was necessary to increase teachers' qualifications to face up to these challenges.

A designer trainer gets in touch with these school actors and conceives with them a training to support a school project about language difficulties.

In this paper, we will present this case study's analysis ${ }^{1}$.

\section{Context}

\subsection{Inclusive Context}

Following different policies published by The Council of the European Union, the country members of the European Agency for development in special needs education have identified as a priority teacher education for inclusion. These country members requested information about the competences and attitudes necessary for all teachers working in inclusive settings (Donnelly \& Watkins, 2010) [1]. By inclusion, they mean that specific capacities must be developed to undertake the appropriate education of pupils with diverse needs.

In this line, in Switzerland, the policies order that most children have to go to ordinary schools instead of specialized schools, i.e. they must attend regular schools in spite of significantly various needs. Therefore, skills to support all children with their differences must be developed in ordinary schools, so that all children could be given an optimal opportunity to benefit from an education in regular classes. For that reason, various professionals have to collaborate to receive very different pupils in ordinary classes and address their specific needs.

1 Six case studies are analyzed in a thesis research. We present in this paper one of them. This thesis research presents different contexts and conception designs: for example «"characteristics of school climate"; "reintegration of teenagers from specialized to ordinary schools", "ongoing training about developmental reading disorder", i.e. dyslexia.» C.f. The references at the end of this paper. 
Hence, school's teachers have a lot of questions and turn towards ongoing training to gain support for reflective practice in order to guarantee such inclusive education.

\subsection{Research Context}

Here, we expose how our institution works, in practical terms, to provide trainings to teachers in this field.

First, school directors, collaborators who are in charge of educational specific sectors and teacher teams request training to discuss their problems and questions related to their daily work, by addressing a written demand to the University of teacher education, sector of ongoing training. Then, this institution proposes various courses and also custom-made trainings. Enlart (2007) [2] shows the importance of training conception and says that «organizations requirements consist of pushing to adapt offer towards custom-made and specific trainings. On the other hand, suitable $[\ldots]$ training sometimes simply does not exist. In all these cases, conception is at the heart of practice » $(\mathrm{P}$. $12)^{2}$.

Then professionals of ongoing training, designer trainers, analyze these requests in collaboration with school actors and create with them original designs to look for answers to their specific questions. During context and demand analysis, interactions and exchanges usually take place between these actors and the designer trainer. A partnership is often established and different tasks are shared out to create a training that will really take into account the specificity of teachers' needs.

\section{Problematic Elements}

\subsection{Custom-made Training}

For us, it is a challenge to understand and follow the reflections and thoughts of designer trainers during the analysis/conception phase and how they determine choices for their design concept. We aim at showing how trainers who design the concept « prioritize » or « underestimate » one or more of the three parameters among those present during the conception (Enlart, 2007) [2] i.e. the various aspects of context, contents and learners. This reference is a real providing clue of our research and we will show this element in this paper. We can also mention that this type of custom-made training have a strong issue i.e. to emphasize on the importance of taking into account problems and questions of the teaching field. It facilitates also training actions built in collaboration and participation with the

2 Les exigences des organisations consistent à pousser vers une adaptation de l'offre, du sur-mesure, du spécifique. D'autre part, la formation idoine, toute prête, n'existe parfois tout simplement pas. Dans tous ces cas, la conception est au cœur du métier. (P. 12)

(Translation by the author) concerned teachers who will have the opportunity to contribute to the creation of their own ongoing training.

\subsection{Research Questions and Hypotheses}

Our research questions focus on the strategies that the designer trainer uses to create a new design, to be as close as possible to the practical context.

1. As analysis process to investigate the situation, we hypothesize that the designer trainer should look for information about teachers' needs and questions.

2. To define conception choices, we propose that he should identify critical factors that may change his points of view and influence his choices.

3. To conceive his original design, we hypothesize that he should create his original design using successive deductions and mobilizing his professional values.

\section{Theoretical Framework}

In the next section, we would like to emphasize on some characteristics of conception work i.e. the necessity for the designer trainer to mobilize his or her reflexivity and the fact that each situation and interactions with the school actors are unique. Therefore, we will explore different aspects, which were shown to take place during conception design, namely reflexive practice and interactions between surrounding factors according to Bandura (2003) [10] or Enlart (2007) [2] respectively.

\subsection{Reflective Practice}

When designing the concept, there is no obvious solution. Consequently, the designer trainer has to make sure to use reflexivity in his or her design practice (Schön, 1983, 1996) [3].

In the literature numerous authors say that the notion of reflexive thought comes from Dewey [4] (i.e. Perréard-Vité, 2003 [5]; Pallascio, Daniel, Lafortune, 2004 [6] Perrenoud, 2008 [7]). According to Perréard-Vité (2003), Dewey considers the reflection as « a form of specialized thought " (p. 40). Dewey emphasizes on the fact that behind every thoughtful operation is hidden a state of perplexity, hesitation, doubt. He also notices that the uncertainty is an element, which stimulates the reflexive thought. «Being unexpected, abrupt and unforeseen, this fact needs to be interpreted, identified, put in its place. » (P. 19). These elements lead to an attitude of inquiry as well as to the adoption of the attitude said " about the suspended conclusion». Thus, Dewey adds that " the essential characters of the reflective thought are: doubt and avoid early conclusions, while pursuing systematically the research » $(\mathrm{P}$. 24).

Also Bourgeois (2013) [8] says that Dewey emphasizes upon the importance of coming and going between thoughts 
and actions. There is a whole interdependence during inquiry between thoughts and concrete operations.

These are in fact very important elements of reflexivity relating to our research subject.

\subsection{A Singular Situation and Different Interactions}

To characterize further the processes underlying the conception choices, it is suitable also to detail the interactions between the different factors in a given situation.

Of note, the meeting between a designer trainer and school actors is always a singular situation. Barbier \& Galatanu (2000) [9] identify three elements in a singular action i.e. active person, environment and types of actions. In socio-cognitivist theory, Bandura (2003) [10] proposes a triangle characterized by interactions between personal factors, behaviors and environment (p. 17).

His point of view aims at showing how human behavior should be characterized by interactions between personal factors, behaviors and environment. These three factors should permanently influence each other.

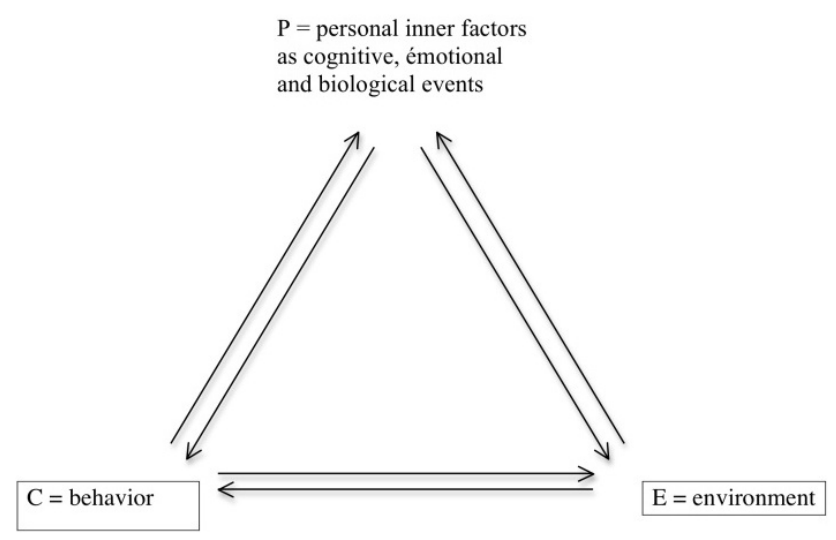

Figure 1. Triadic reciprocal causality (Bandura, 2003) [10]

What we can keep from this model are the interrelations between three poles. Individual is indeed characterized by personal capacities inciting him to commit himself more or less in the action, by previous behaviors and experiments.

This person interacts with his or her environment by showing a behavior, which seems appropriate. Environment influence such behavior and individual will reciprocally influence this environment. According to Bandura (2003) [10], there is thus reciprocity, but it « does not mean that these three groups of factors have the same impact. Their relative influence can vary according to activities and circumstances.» (P. 17) A temporal factor is important too. Besides, this model can be applied to all human activities.

\subsection{Conception of Training Design}

Consequently, we suggest that designer trainers of our research are involved in such processes. By the training request, they enter into a new environment, mobilize their own perceptions and values, decide to do some actions. In the following section, we will focus on conception activity itself; we aim at showing the complexity of this work and the different interactions, which characterize this activity.

Enlart (2007) [2] proposes a triangle (figure 2), which places conception in the center and associates three parameters: context, contents, learners. (p. 51)

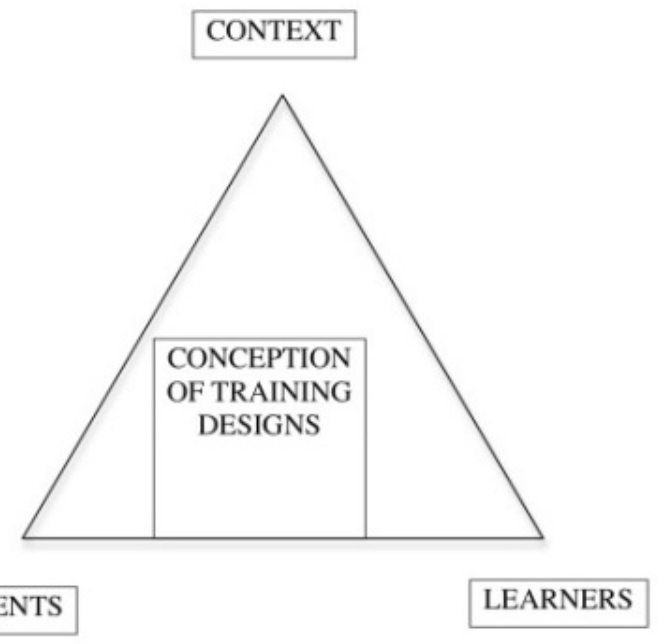

Figure 2. Conception of training design: a specific activity

In the center is conception. We would say that the designer trainer is placed in the center and interacts with these three poles. In a best case, it seems that these poles could balance each other or in a less favorable case, they could shade mutually according to the importance the designer trainer would attribute to them. But it seems that in the case of this triangle, the main interrelations take place rather between the center and the poles. Indeed, the designer trainer is going to build himself a representation in relation to the singular situation. These elements are fundamental according to conception choices.

At this point of our thought, we focus on a singular situation i.e. a designer trainer, Fabian, interacting with the school actors particularly a dean and a group of professionals.

Clottu (2013) [11] proposes to add to Enlart's figure elements showing interrelations between the parameters as well as time necessary to create a design (figure 3 ). The time necessary to create a design is relatively long for example several weeks or even several months.

Fabian $^{3}$ expresses $^{4}$ this fact like that:

- As we are on a school project, it is necessarily long. I want to say, it is like a ship which we have to make turn, to change course. A big ship needs space and time. There are a lot of individuals to coordinate.

3 Fictitious first name

4 Fabian's words are translated by the author. 




Figure 3. Conception of training design: interrelations and time (Clottu, 2013, p. 38) [11]

\section{Context}

A project is undertaken where specialized teachers go into three classes to support the pupils and teachers.

Children's families come from complex social situations and a lot of them speak another language at home.

A member of the direction council is in charge of education and training in the school. He sustains the project.

Contents

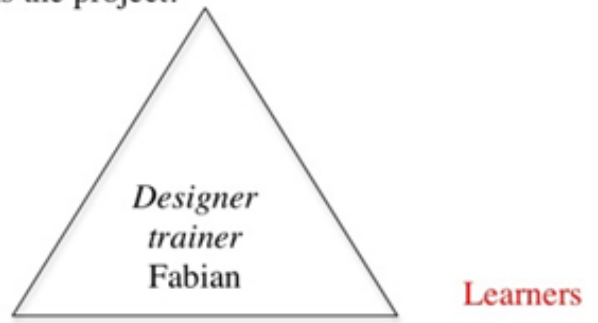

Teaching about language difficulties and reading ;

Taking into account the differences between children for example cultural differences ;

Let pupils learn through comprehension of their errors without highlighting that they have made faults.

The team of teachers have good communication and collaborate together.

The teachers are stressed and tired : they need to have the opportunity to speak about their difficulties, analyse their practices, develop a reflective practice.

Figure 4. Critical factors identified by Fabian

Therefore, the designer trainer examines successively and in interaction with the school actors which elements are relevant in the situation he or she has to analyse relating to context, contents or learners. Are there some substantial difficult problems, some characteristics that he or she has to treat during analysis? Which of these elements will be the most important during the phase of creating the design?

\subsection{Critical Factors}

In design conception, we can identify some critical factors, meaning that these three parameters are taken into account with diverse ways. In fact, some critical factors related to these parameters appear as problematic or essential. " If "something" is particularly relevant, then, the other things lose their relative importance, and the design will be thought relating to the critical factor. » (Enlart, 2007, p. 53). ${ }^{5}$

The author states that the way designer trainers articulate these parameters have an impact upon conception choices.

5 « Si "quelque chose" est particulièrement marquant, alors le reste perd de son importance relative et c'est autour du facteur critique que l'on va penser le dispositif.» (Enlart, 2007, p. 53) 
Some examples from the case study illustrate how Fabian perceives these critical factors related to the situation of the teachers who have requested ongoing training (figure 4). These are not described always as problems but also as essential positive factors.

\section{Data Collection and Analysis Method: A Qualitative Approach}

Our choice is to realize a qualitative research with a case study. This approach will allow in-depth points of view upon the situations. Before detailing further our data collection, we will first present briefly the five existing types of qualitative approaches, in order to take a step back and better highlight the specificity of our method.

\subsection{Five Qualitative Research Types}

To precise the methodology of our research, we refer to Cresswell (2007) [12], who distinguishes five qualitative research types.

\subsubsection{Narrative Research}

«Studying one or two individuals, gathering data through the collection of their stories, reporting individual experiences, and chronologically ordering [...] the meaning of those experiences» (p. 54).

\subsubsection{Phenomenological Research}

«A phenomenological study describes the meaning for several individuals of their lived experiences of a concept or a phenomenon.» (P. 57)

\subsubsection{Grounded Theory according to Strauss \& Corbin (1998) [13]}

«A key idea is that this theory development does not come "off the shelf", but rather is generated or "grounded" in data from participants who have experienced the process.» (P. 63)

\subsubsection{Ethnographic Research}

«The researcher describes and interprets the shared and learned patterns and values, behaviors, beliefs, and language of a culture-sharing group.» (P. 68)

\subsubsection{Case Study}

«The investigator explores a bounded system (a case), or multiple bounded systems (cases) over time, through details, in-depth data collections involving multiple sources of informations.» (P. 73)

After having examined these fives qualitative research types, we have decided to realize our research using the case study type even if we can identify some common aspects in the other approaches (e.g. concerning narrative research: chronological story; concerning ethnographic research: participating observation).
Hence, given that we observe a designer trainer as he or she analyses a request from a school. In fact, the «case study» type seems the most nearby of our research. Indeed, the situation of a case study constitutes a limited system. The beginning and the end are clearly defined. The beginning is when the designer trainer receives the written request. The end is when the training is finished. The data are various and collected during the whole process of demand analysis as well as during the different phases and right to the end of the training. This approach gives the opportunity to observe the trainer in connection with a very precise request.

\subsection{Data Collection}

Fabian is a teacher who is specialized in the field of adult education. He is in interaction with a school located in a small town where everyday life is not easy when considering economic, cultural and social points of views. He creates interactions based on a clear and transparent communication.

To collect data during the case study, written documents, which show, how Fabian designs the concept, are collected, for example, e-mails exchanged with the dean. Fabian and the dean consented to give us all e-mails. Hence, we were able to follow all the communications during the analysis/conception phase.

At the middle of the training, we collected assessment documents, as well as at the end of the training.

After the end of the training, we met Fabian for a relatively long interview according to Vermersch approach (1994, 2000) [14] named explicitation interview. It was also carried out to emphasize on the conception choices and the originality of the design as well as on Fabian practices during the analysis/conception phase until the end of the training.

\subsection{Data Analysis}

Data were organized according to a chronological order. Interview was recorded and transcribed while quotations were classified according to the following frame.

We based our analysis originally on the Enlart triangle (2007) [2] described above, which has been used to establish categories according to Miles \& Hubermann (2003) [15], who indicate that «codes are labels, which appoint signification units for descriptive and inferential information compiled during a study.» (p. 112) ${ }^{6}$ Hence, we have taken into account, as starting points, Enlart's three parameters, refining them to elaborate our analysis frame as follows.

\subsubsection{Context}

According to context (figure 5), we have considered different under categories, such as large elements defined such as Swiss and state of Vaud legal aspects. Then, we have considered middle elements such as school characteristics,

6 «Les codes sont des étiquettes qui désignent des unités de signification pour l'information descriptive ou inférentielle compilée au cours d'une étude.» (Translation by the author) 
(organization, pupils populations) and school direction (leadership type). Micro elements refer to communication and relations between the actors.

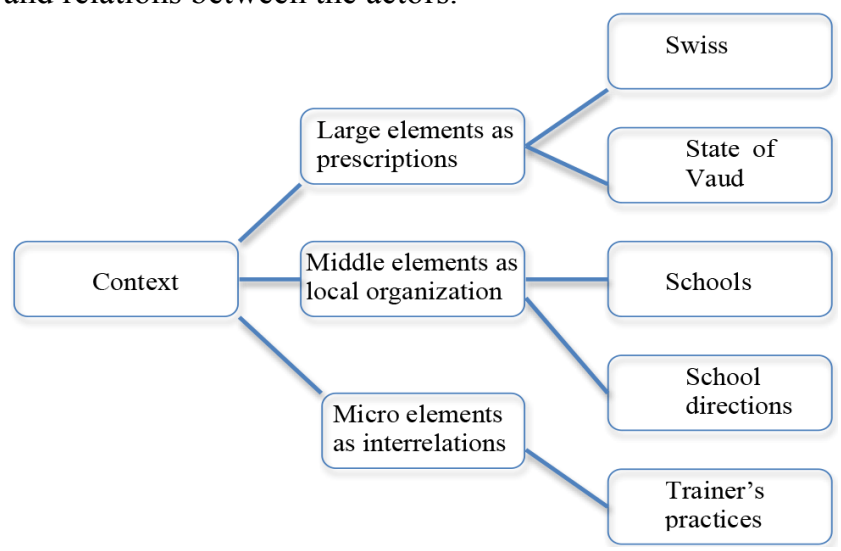

Figure 5. First parameter: context with under categories

For example, here are two quotations from Fabian related to school characteristics:

- At the beginning, there were only two or three classes. The simple fact that we transform these practices into training, it affected the whole school. Thus it made a lot of people.

- The situation was difficult before the beginning of the training, even before they made the request. The situation was this one: pupils' strong proportion of other cultures, and destabilization of the teachers; pupils who had behavior or learning difficulties.

Here is a quotation from Fabian in relation to school direction (leadership type):

- There are direction councils, where they say what they are doing, thus the director knew, and by delegation, the dean had practically directorial mandate, and then that worked well.

\subsubsection{Contents}

According to contents (figure 6), we have considered general elements (large themes) and specific elements (after demand analysis, contents taught during the training).



Figure 6. Second parameter: contents with under categories

Here is a quotation from Fabian in relation to training specific contents:

- At the very beginning, we had realized that it was necessary to work on certain fields, for example the co-teaching between special and ordinary education.

\subsubsection{Learners}

According to learners (figure 7), we have considered collective dimension and individual dimension.

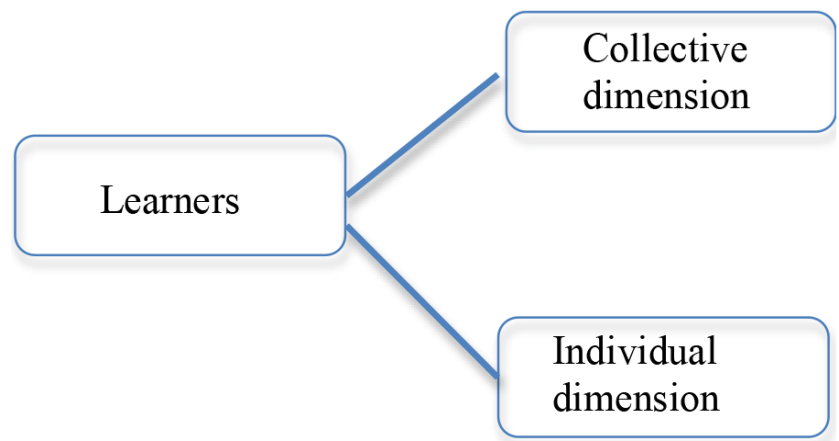

Figure 7. Third parameter: learners with under categories

Here is a quotation from Fabian in relation to teachers in a collective dimension:

- It was really the project of people who were there. They had long-lived questions relating to their situation, they explained the problems how they perceived them.

\section{Results}

Our research has shown some relevant elements about work processes, conception choices and inferential reflexion to build the design. In this next section we will present the main elements.

\subsection{Processes for Analysis}

The research revealed that Fabien's work processes focus on relational aspects (open communication channels, trust, attentive listening), the use of formal aspects to frame and give rigorous order (written document formalizing the design), the circulation of information at each emergence of a new element to ensure the acceptance of teachers, the frequent use of e-mail to frame, the accompaniment of the requesting and reflective team by taking the time necessary to this realization.

Here are some quotations to illustrate these results:

- Interrelations constitute themselves and on the basis of these relationships, then, the canals are open and we will be able to work the fundamental questions.

- I am not listening to you so that you would say «but everything is okay». I am listening to you so that you tell me what you did and how you did it and which was the result. In short, I have a listening ... I convey the idea of a careful listening to solve the problems if there are some which could come.

- When I am in the analysis of a request like this, I accompany the requesting team.

\subsection{Conception Choices}

Our research has shown that the way Fabian has identified 
critical factors (figure 4) is directly related to the choices he will operate. So, in the next section, we will remind theses critical factors and put write in italic characters the conception choices according to Enlart's three parameters (2003) [2] and to the above described analysis frame.

\subsubsection{Context}

A project was created with specialized teachers going into three classes to support the pupils and teachers.

The design favors real training, not only punctual support but all classes in the school should participate to the project.

The children's families are in difficult social situations and a lot of them speak another language at home.

As this context is similar for all teachers, the design plans that all teachers would engage themselves in the training.

\subsubsection{Contents}

Teaching about language difficulties and reading.

Theoretical elements will be taught at first to teachers, analyzing a first general level of professional situations.

Take into account the differences between children, for example cultural differences.

Practice analysis will take place every six weeks to fully understand actual pupils' situations in their classes.

Let pupils learn through comprehension of their errors without highlighting their mistakes.

Contents have to integrate a transversal dimension not only a didactical dimension, for example, errors analysis, observation, learning strategies.

\subsubsection{Learners}

The teams of teachers have a good communication and collaboration together.

The design will provide for regular organized time for exchanges about professional situations.

The teachers are stressed and tired: they need to have the opportunity to speak about their difficulties, analyze their practices, develop their reflective practice.

Reflective practice has to be developed in the whole design by a lot of exchanges in little groups and also during the daily work with pupils.

Accompaniment before and during the training is absolutely necessary.

The learners will be in reflective situations at every moment and have the possibility to analyze their difficulties with pupils in interaction with specialized colleagues.

Design choices result from both context analysis (pre-existing project, need to deal with difficult professional situations) and Fabian's personal design style («compulsory» companion dimension, long-time work, integration in practice). Fabian makes the choice to consider teachers as partners. It will not be a training in spite of them but with them. A strong emphasis is placed on work based on real-life situations and on the reflexivity to be developed from these situations. Even if these are difficult, it is necessary to develop reflexivity seeing them with diverse points of view.

\subsection{Designer Trainer's Reflexivity}

When we have analyzed our data, we noted elements about the designer trainer's reflexivity as well as the impact of professional values in conception work. These have a strong influence upon the conception choices.

Fabian's intuitions are related to relational elements. He perceives the characteristics of people, ensures that there is no misunderstanding or hidden element that is not spoken to him. He can thus trust and move forward. This perception of people often takes place in informal moments. This also gives him reflexivity about the situation. But he has developed also reflexivity about his role and learning in this activity.

Concerning his professional values, the one element he thought to be the most essential in relation to all training designs was the accompaniment at all times. He expresses this element in these words:

- I believe in the training by accompaniment. This is the way I do the main part of my work of trainer. [...] I propose accompaniment because for me it seems a model, which works very well.

But we can also identify other professional values as clear communication, careful listening. We can even say empathy and add collaboration during the whole conception process.

\subsection{Synthesis of Design}

Fabian qualifies the design as fitting just like « a Russian doll» (figure 8).

- There was co-teaching in the classes, there were small groups, and at different moments, these small groups had meetings all together. Thus it makes a rather rich structure. [...] Yes, Russian doll, there is a Russian doll effect.

- This design shows that the teachers are practically permanently immersed into the treatment of difficulties, rather than facing them daily without mobilizing reflective practice and looking for new solutions. There is an idea of continuity of the reflection and accompaniment. 


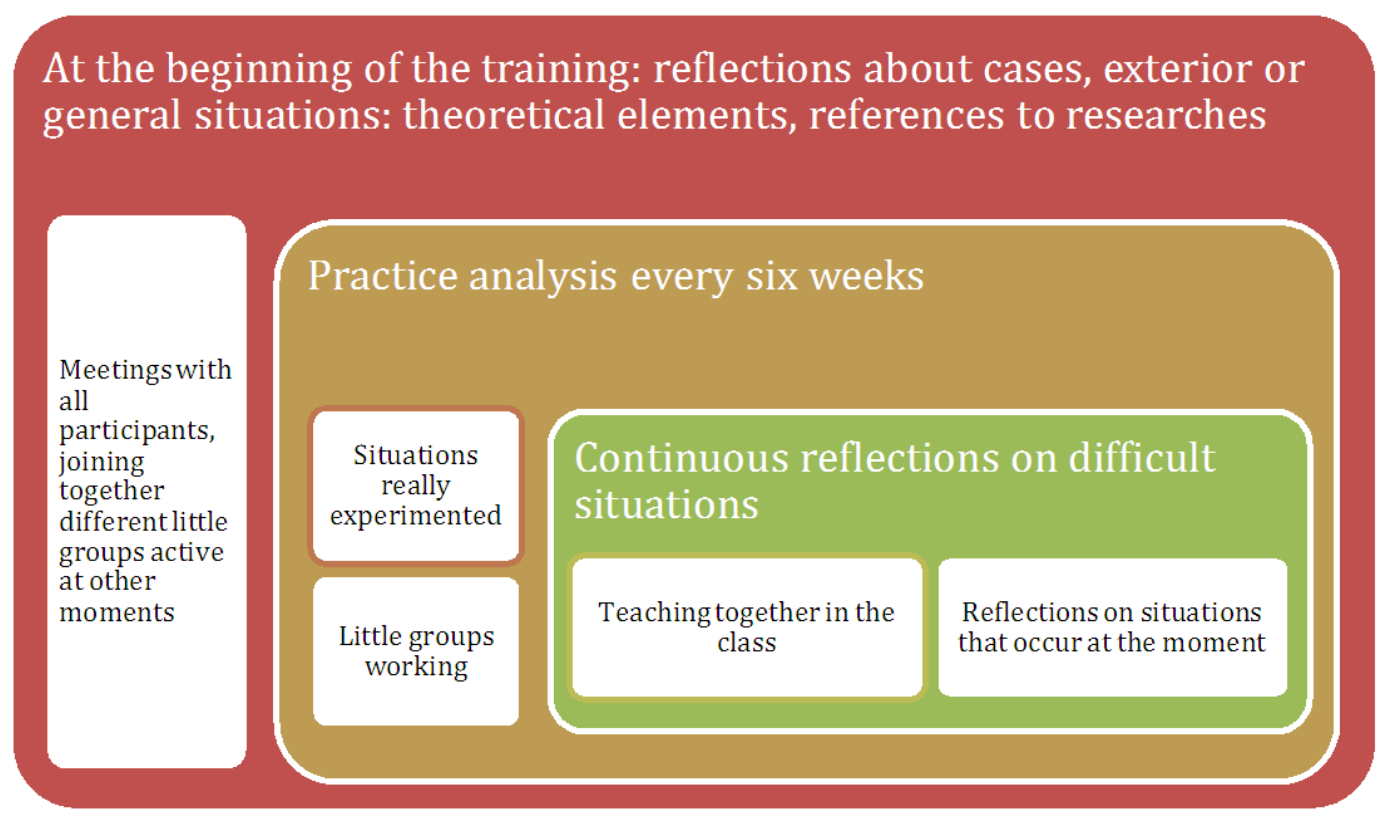

Figure 8. An original design

The red part concerns meetings with all participants. The brown part involves practice analysis in little groups. The green part concerns situations that occur in the class at the moment.

Time organization is very important too. The activities mentioned in the red part of the figure took place from April to June. The activities mentioned in the brown and green parts took place during the whole year after.

Fabian's design presents a clear structure as well as in terms of modalities (plenaries, work in small groups, accompaniment in classes) and temporality (first phase, second phase, variable frequency of modalities). It foresees a progression, namely, the initiation of reflection and nourishing inputs for the first phase, continuous support with feedback and targeted academic inputs and links with practice, for the second phase. The evaluation of the design process and the effects of the training are done by two assessment sheets transmitted by the dean.

\section{Discussion}

In this article, we have emphasized upon three questions.

The first question concerns processes used by Fabian to create a design.

Communication and reflexivity with a team inside the school seem essential elements of these processes. We could say that a team is a necessary condition to create a design that would have a chance to answer teachers' questions. These could propose new contents, express their difficulties and benefit from listening and empathy. After our research, we could say that this point should be generalized in other trainings.

Another relevant point if the different actors develop reflective practice is the necessity to foresee time for conception work with the team that has requested a custom-made training. Information must be available to every concerned person, who could react and make proposals. Teachers have to receive information about each conception choice. A project in a school is «a big boat», which needs time to move. In a timely point of view, seven month were necessary to build the training design, while the whole training design process was worked out during a total of one year and a half. Even if it was possible to react and build a frame at distance, a meeting was necessary between all the partners in order to be able to begin the training. We could emphasize on this point that oral communication during meetings is indispensable generally regarding to conception processes.

The second question concerns the different choices that founded the design.

Are there some substantial difficult problems, some characteristics that have to be treated during analysis? Which of these elements will be the most important during the phase of creating the design? First of all, Enlart (2007) [2] says that conception has to take into account three parameters, context, contents and learners. But « what does take into account mean? Which priority do we have to give to each of these elements? » (p. 51). We will now focus on these priorities.

Concerning context, Fabian's conception practices show that the school context is rather positive. Notably, specialized professionals accompanied some teachers, while in general colleagues have a good communication together. Pupil's general characteristics and specific difficulties were also well identified. We noticed that the dean is a very important actor to sustain teachers, who feel concerned by the training. This context with its characteristics was a real support for the future training. Therefore, this aspect of our 
study shows the importance of the pre-existing context for the success of training design, and the crucial choices according to this context required from the designer trainer reflexivity and actions to build the training.

Concerning contents, he has taken into account general aspects related to pupils' difficulties, in French language e.g. reading and vocabulary but also what the dean and teachers have proposed during the conception phase e.g. error analysis, learning strategies, migration problems. During interactions between teachers and other partners as well as specialized teachers or speech therapists, and with the dean, these new contents were identified. Our study has shown that even if contents are really didactic, some other implicit contents focus on personal reactions in the situation and representations about pupils and families. We could emphasize on the fact that these two contents types are present in each design conception.

Concerning learners, Fabian was very deeply concerned about teachers' practices. So he has provided for time to participate to discussions about future training and for different practice analyses. He relives that teachers should be partners during the conception phase and the whole training. He wants to be an interlocutor who could open for them new perspectives. Hence, Fabian becomes really for the school actors a "reflective companion », who inducts reflexivity guiding a practitioner to see situations with other points of view and walking together around common projects. (Donnay \& Charlier, 2008) [16]

The third question concerns the designer trainer's reflexivity.

Our data highlight that Fabian reflects on his own activity as well as on the situation of the school. He speaks about his role in conception work. He says: « I act as a sting to listen teachers on precise points $»$. He brings rigorous order to frame the project. Related to the situation of the school, some questions appear. How to build the design developing what does exist previously? How complete information? How to extend the project to all classes? If some new contents are identified, where find specialists to give teachers theoretical and practical inputs? The real challenge for the training was to meet teachers' needs and questions, to act as well as possible on the representations that teachers have upon their work. Thus, practice analysis was a very important conception choice. Another relevant aspect is the impact of professional values as explained above. Reboul (2005) [17] says that in every domain a value is something that merits efforts, care and personal implication. So accompaniment for Fabian is a real professional value. This has an impact on all the designs he creates. In fact, he has been conceiving designs, answering to professional's requests for more than sixteen years. Thus, as Fabian emphasized on the necessity of clear communication, he tried to take into account every suggestions from the different partners. Probably, professional value may be diverse for different designers, trainers, but clearly, this case study shows their importance.

We want to mention another study that was developed in Geneva by Vanhulle \& al. (2008) [18]. Teachers had become trainers and accompanists in schools. They have learned this new activity by doing and were invited to qualify this work. They emphasized on three characteristics groups necessary for accompanying teachers: i.e. reflexivity, communication, analysis and negotiation. These three characteristics are really nearby Fabian's conception practices.

All these findings give elements to potentially generalize in other trainings on demand as well as in training for new designer trainers.

\section{Conclusions}

This research has shown some elements about a work not very known, however, a lot of teachers have questions that merit to be treated during trainings. This case study emphasizes on the importance of time for reflexivity but not only informal time, but time really organized for practice analysis. Practice analysis is progressive. In fact, the design proposes to begin with general professional situations, continue with situations from their own practice to discuss in little groups, and continuously, reflect in depth about situations that occur at the moment in the daily work. These different levels during the training enable intensive reflexivity.

Our case study shows that conception work needs to have an analysis/conception phase that will benefit of the fact that teachers should be real partners and thus participate to the building of their own training

So, the training has stimulated reflective practice and experimentation. It has provided a framework to integrate new approaches. However, Fabian has the preoccupation that the teachers should pursue their progression after the training.

He proposes that trainers should continue to accompany teachers less and less until they will be able to practice new approaches and see their pupils with other points of view.

This case study highlights, according to Bandura (2003), and related Fabian's conception work, that personal factors as intuitions, reflexivity and professional values (personal inner factors) progressive consciousness of the characteristics of the situation (environment) and actions in the school (behaviors) are intimately bound together. Following Dewey (2003) and Bourgeois (2013), we can say that conception work is a real inquiry with coming and going between thoughts and actions.

Even if other analyses would be necessary to improve further our understanding of the processes underlying training design, this case study brings significant elements to the field of continuous training, allowing us to promote and develop this kind of training.

\section{Acknowledgements}

To Fabian for having accepted to share his conception practices. 
To the Direction of University of Teacher Education in Lausanne-CH, for time given to write and publish.

To Aurélie S. Clottu for her reading, comments and suggestions during the creation of the manuscript.

\section{REFERENCES}

[1] Donnelly, V. \& Watkins, A. (2010). Une agence européenne pour soutenir l'éducation inclusive. Prismes, Revue pédagogique de la HEP Vaud, 13. English title: European Agency for Development in Special Needs Education.

[2] Enlart, S. (2007). Concevoir des dispositifs de formation d'adultes: du sacre au simulacre de changement. Paris: Editions Demos.

[3] Schön, D. (1983). The reflective practitioner. How professionals think in action. New York: Basic Books.

[4] Schön, D. (1996). A la recherche d'une nouvelle épistémologie de la pratique et de ce qu'elle implique pour l'éducation des adultes. In J.-M. Barbier (Ed.). Savoirs théoriques et savoirs d'action. (201-222). Paris: PUF.

[5] Dewey, J. (French version: 2004). Comment nous pensons. Paris: Le Seuil.

[6] Perréard Vité, A. (2003). Réfléchir sur sa pratique: études de cas pour la formation initiale et continue des enseignants. Genève: thèse en sciences de l'éducation.

[7] Pallascio, R., Daniel, M.-F. \& Lafortune, L. (2004). Une pensée réflexive pour l'éducation. In R. Pallascio, M.-F. Daniel, et L. Lafortune. Pensée et réflexivité, Théories et pratiques. Sainte-Foy (Québec): Presses de l'Université du Québec.

[8] Perrenoud, P. (2008). Développer la pratique réflexive dans le métier d'enseignant, professionnalisation et raison pédagogique. Paris: ESF Editeur.
[9] Bourgeois, E. (2013). Expérience et apprentissage. La contribution de John Dewey. In L. Albarello, J.-M. Barbier, E. Bourgeois \& M. Durand. Expérience, activité , apprentissage (9-14). Paris: PUF.

[10] Barbier, J.-M. \& Galatanu, O. (2000). La singularité des actions: quelques outils d'analyse. In J.-M. Barbier \& al. L'analyse de la singularité de l'action. Paris: PUF.

[11] Bandura, A. (2003). Auto-efficacité. Bruxelles: De Boeck.

[12] Clottu, R. (2013). Pratiques de conception de formations à la demande et apprentissages en situation de travail de conception: six études de cas dans le contexte de la formation continue des professionnels de l'enseignement. Co-direction: Sandra Enlart and Etienne Bourgeois. Thèse de doctorat: Univ. Genève, 2013 - FPSE 541 - 2013/09/05, available (except some appendices) on: http://archive-ouverte.unige.ch /unige:30818"> http://archive-ouverte.unige.ch/unige:30818

[13] Cresswell, J. W. (2007). Qualitative inquiry and research design. London: Sage Publications. Ltd.

[14] Strauss, A. \& Corbin, J. (1998). Basics of Qualitative Research Techniques and Procedures for Developing Grounded Theory (2nd edition). London: Sage publications.

[15] Vermersch, P. (2000). Approche du singulier. In J.-M. Barbier $\&$ al. L'analyse de la singularité de l'action. (239-256). Paris: PUF.

[16] Vermersch, P. (1994). L'entretien d'explicitation. Paris: ESF.

[17] Miles, M.B., \& Huberman, A.M. (2003). Analyse des données qualitatives. Paris: De Boeck.

[18] Donnay, J. \& Charlier, E. (2008). Apprendre par l'analyse de pratiques: initiation au compagnonnage réflexif. Namur: Presses universitaires de Namur.

[19] Reboul, O. (2005). Les valeurs de l'éducation. Paris: PUF.

[20] Vanhulle, S. \& al. (2008). Formateur/accompagnateur en milieu scolaire: une profession en attente de reconnaissance. Travail et Apprentissage, Revue de Didactique Professionnelle, 2, 25-45. 